\title{
ORTEGA Y GASSET Y LOS INICIOS DE LA VANGUARDIA ARTISTICA ESPAÑOLA
}

\author{
Rafael LORENZO ALgUEZAR \\ Centro Universitario de Teruel
}

Los primeros escritos de Ortega son de estética o más bien de critica literaria. Influenciado por Nietzsche y Unamuno repasa con claros acentos románticos algunas obras y autores de actualidad. Curiosamente en uno de ellos Publicado en El Imparcial el 6 de agosto de 1906 y titulado "Critica bárbara", defiende con cierta vehemencia, en contra de los poetas preciosistas y formalistas, el arte comprometido con la vida humana y con la realidad española. el arte que nos llegue dentro y que nos produzca sensaciones y emociones. Frente al formalismo y al preciosismo, dice entonces, debe ejercerse la crítica bárbara. Y digo que es curioso porque posteriormente Ortega va a arremeter en buena medida contra las caracteristicas de ese arte que ahora defiende'. Posteriormente su contacto con el Neokantismo y su ruptura con el 'africanismo' de Unamuno le hará tomar posiciones más sistemáticas en estética y que merecerán nuestra atención enseguida. Naturalmente no es momento aqui de analizar su relación con Unamuno, ni sus muy diversas consideraciones estéticas sobre España. Tocaremos sólo los temas que nos parezcan imprescindibles para centrar la posición de Ortega frente a las vanguardias artisticas.

\footnotetext{
1 Véase "Moralejas I" en ORTEGA Y GASSET, José, OBRAS COMPLETAS vol. I Alianza Editorial. Revista de occidente. Madrid 1983 (en adelante O.C con el vol en números romanos y el número de página). Véase también MORON ARROYO, Ciriaco, El sistema de Ortega y Gasset, ediciones Alcalá Madrid 1968 p. 364.
}

Endoxa: Series Filosóficas. n 1. 1993, UNED, Madrid:

Rafael LORENZO ALQUEZAR. Ortega y Gasset y los inicios de la vanguardia artistica española pp. $309-338$. 


\section{1.- Adán en el paraiso: la estetica neokantiana}

El primer escrito sistemático sobre estética de Ortega ha sido objeto de abundantes comentarios entre sus estudiosos: Todos admiten que la influencia Neokantiana es fundamental. Para Julián Marias $^{2}$ están en este escrito algunas de las ideas básicas del pensamiento de madurez, sobre todo aparece tratada de forma importante la idea de vida que es vista por el discipulo de Ortega como anuncio del concepto de vida como realidad radical propio de las principales obras de Ortega. Morón Arroyo ${ }^{3}$ reconoce la importante influencia de Cohen y Natorp, pero se extraña de que la Estética de Cohen es de 1912 siendo que el artículo es de 1910 , aunque justifica la influencia del maestro en el discipulo por que Ortega habia asistido al curso de Cohen sobre Estética en 1907. Nelson Orringer propone una nueva lectura del artículo basándose en que Ortega habia manejado un texto de Cohen de 1889 titulado Kants Begrundung der Aesthetik ${ }^{4}$ Ortega comienza confesándose lego en pintura y reivindicando la necesidad de los prejuicios para una auténtica interpretación-comprensión del arte. Ver el arte sin prejuicios es la postura del Orangután, es decir la posición natural e inhumana. El hombre se forma en una tradición y esa tradición es conformadora de prejuicios.

"Sin prejuicios no cabe formarse juicios, en los prejuiclos y sólo en ellos, hallamos los elementos para juzgar. Lógica, ética y estética son literalmente tres prejulclos, merced a los cuales se mantiene el hombre a flote sobre la superficle de la zoologia y libertándose en el lacustre artificlo se va labrando la cultura liberrimamente, racionalmente, $\sin$ intervenclón de misticas substanclas nl otras revelaciones que la revelaclón positiva sugerida al hombre de hoy por lo que el hombre de ayer hizo. Los prejulclos iniciales de los padres producen una decantación de julcios que sirven de prejuicios a la generación

${ }^{2}$ MARIAS. Julián Ortega I, Circunstancia y vocación. Alianza Universidad. Madrid 1984, p. 323 ss.

${ }^{3}$ MORON ARROYO Ciriaco, El sistema de Ortega y Gasset, Ed. Alcalá, Madrid 1968 p. 365 ss.

${ }^{4}$ ORRINGER Nelson R., Ortega y sus fuentes germánicas. Gredos Madrid 1969 Capitulo I. 
de los hijos, y asi en denso crecimiento en prleta solidaridad a lo largo de la historla. Sin esta condensaclón de prejuicios no hay cultura!"5

Interesante reivindicación del prejuicio desde la perspectiva neokantiana e interesante precedente de la hermenéutica gadameriana. Ciertamente las ciencias puras son las que nos permiten comprender la realidad desde sus esquemas y prejuicios. Este es un punto claramente neokantiano e idealista que Ortega superará posteriormente. Cosa distinta es el prejuicio tradicional como conformador de la cultura, y no desde la idea reflexionada de la ciencia, sino desde la prerreflexividad de la creencia. Esto que ahora se enuncia aqui de forma un tanto oscura puede ser una idea fundamental en el futuro Ortega que lo relacione de forma decisiva con la fenomenologia.

Enseguida Ortega distingue entre la realidad cotidiana (mundo de la vida ordinario) donde encuentro relaciones laxas, aproximativas etc. y la realidad científica donde se requiere precisión y exactitud.

La unidad propia del cuadro el punto de vista especialmente pictórico no debe ser ni sociológico, ni filosófico ni matemático, debe ser específicamente pictórico. Ortega se plantea investigar y definir el ideal de pintura. Este problema y sus intentos de solución van a condicionar la posición de Ortega al considerar el nuevo arte o el arte de vanguardia, que sólo puede ser comprendido asumiendo un punto de vista intrinseco al arte mismo, es decir un punto de vista artístico. La solución que aquí va a apuntar es un concepto muy importante para toda su obra posterior, más allá de la propia teoria estética. Es la cuestión de la vida:

"El hombre es el problema de la vida (...) La vida de una cosa es su ser"6

Frente a las abstracciones de las ciencias y a sus leyes generales y exactas que se ejemplifican en las cosas, la vida es lo individual y lo concreto. lo incomparable y lo único. Lo individual no es, pues objeto de la ciencia, es el campo especifico del arte. Por ejemplo la

\footnotetext{
${ }^{5}$ Adán en el paraiso O.C. p. 474.

${ }^{6}$ O.C.. p. 481 .
} 
tristeza. es distinta a la idea de tristeza e incluso las aproximaciones científicas y de todo tipo que se puedan hacer a la tristeza. y mi tristeza concreta que es la auténtica la individual, la concreta y la particular, es decir la vital.

Las cosas están compuestas por haces infinitos de relaciones, las ciencias intentan analizar cada una de ellas, pero su tarea es interminable. Ortega dice aquí que donde acaba la ciencia comienza el arte lo que considero una clara falsedad. La ciencia y el arte son dos formas distintas de aproximación a la realidad de las cosas. con métodos diversos, pero no continuación uno de otro (parece obvia la influencia kantiana).

En cualquier caso para Ortega es claro que el arte no debe imitar a la naturaleza, sino que el arte tiene su ámbito propio que es el de lo especifico lo concreto, lo particular y lo vital. La individualidad sólo es abordable por el arte. No por lo ciencia. "La biografia es un género poéticon. Parece necesaria la referencia a Dilthey, al que Ortega no conoce todavia.

Tampoco el arte puede expresar la totalidad de las relaciones que constituyen las cosas. Por eso el arte es un artificio, la creación de una totalidad virtual. Una infinitud, una plenitud y una absolutez plena que no alcanzamos de ninguna otra de las maneras, pero que es artificial, creada.

"Por consiguiente, lo que debe proponerse todo artista es la ficclón de la totalidad; ya que no podemos tener todas y cada una de las cosas, logremos siquiera la forma de totalidad. La materialidad de la vida de cada cosa es inabordable: poseamos al menos la forma de la vida"7.

Alusión a P. CEZANNE del que dice que nunca pintó bien, pero que nadie ha visto como él el sentido radical de la pintura. Toma el concepto 'realizar' del pintor francés y lo pone frente a las ideas de realismo e idealismo en pintura. 'Realizar' es individualizar, y hacer una concreción expresiva de la totalidad.

${ }^{7}$ O.c.. I. p. 484. 
El arte es construcción. El artista armoniza los distintos elementos, espaciales en las artes plásticas, temporales y sonoros en la música etc.

"Pintar algo en un cuadro es dotarlo de condiciones de vida eterna"8.

El arte efimero no sobrepasa las circunstancias concretas de su tiempo, el arte clásico Lleva en si mismo la carga de eternidad. el pintor debe pintar "las condiciones perpetuas de vitalidad"9.

Ante este articulo seria interesante reseñar la introducción interesante del concepto vida, y la influencia kantiana y aún hegeliana en las cuestiones de estética.

\section{2.- Contrariedades en la estética neokantiana: arte de este mundo y del otro.}

En una serie de articulos publicados en El Imparcial entre el 24 de julio y el 14 de agosto de 1911, nuestro autor retoma los principales elementos de la estética neokantiana, llevando a algunos a su mera contradicción.

Ortega comienza citando la idea profesada por los principales personajes de la cultura española de que el español es realista. Esta idea va a ser ampliamente criticada por nuestro autor y va a dar pie a las distintas manifestaciones del arte y entre ellas las del arte como abstracción de la realidad.

Citando a Worringer y su Historia del arte gótico con el cual dice tener muchas coincidencias, pasa a describir un arte gótico (también español!) y a hacer consideraciones diferenciales sobre el pathos gótico , abstracto, imaginario idealista, místico a veces (Ortega muestra sus pocas simpatias hacia el misticismo), y el pathos del sur, naturalista y realista.

Critica la idea de que el arte sea mera imitación de la naturaleza o mera técnica de imitación del natural.y vuelve a definir el arte como modo de conocimiento.

\footnotetext{
${ }^{8}$ O.C... 1, p. 491.

${ }^{9}$ O.C... I. p. 492.
} 
Critica la idea de que el arte sea mera imitación de la naturaleza o mera técnica de imitación del natural.y vuelve a definir el arte como modo de conocimiento.

"No es un juego nl una actlvidad suntuarla. (...)Es una operación espirttual tan necesarla como la reacclón religiosa o la reacción clentifica" ${ }^{\prime 10}$.

Aprecia la crítica de Worringer a la estética alemana de que está formada sólo a partir de las categorias del arte clásico grecolatino y que es incapaz de apreciar incluso su propia capacidad autóctona de crear belleza: el arte gótico.

El concepto de Einfühlung es central en la estética alemana. Ortega propone la traducción por simpatía. La simpatía aplicada al arte daria como resultado la apreciación de un arte naturalista que intentara llevar al hombre a las formas vitales que le hicieran plenificarse a si mismo como ser vivo. Frente a ello y citando a Worringer, Ortega señala que frente a la simpatia tiene una misma importancia el concepto de abstraccion como motor estético. Ese sería un principio fundamental para entender el arte gótico, por su carácter mistico abstractivo y espiritual, pero al propio tiempo será un elemento fundamental para comprender algunas de las nuevas vanguardias artísticas.

En un capítulo posterior ( $E l$ arte primitivo) recoge Ortega la negativa de Worringer a considerar arte las pinturas de Altamira. En esta incomprensión de Worringer se puede cifrar el inicio del abandono de Ortega de la estética neokantiana y su búsqueda de nuevas teorias estéticas que dieran cabida a la comprensión de lo que para nuestro autor eran auténticas pinturas artísticas. Unas pinturas que para el autor alemán serian mero instinto de imitación, pues el inicio del arte debe ser abstracto y no naturalista. Sin embargo para Ortega son auténtico arte

"más todavia, una postura genuina ante el mundo, una metafisica que no es la abstractiva del indoeuropeo, ni el naturalismo racionalista clásico, $\mathrm{nl}$ el misticlsmo orlental. (...) Yo llamo a este fondo Insobornable de nuestra alma mediterranismo, solicito para el

${ }^{10}$ O.C.. l. p. 191. 
El español, y su arte se interesan por las cosas, por las simples cosas en su sencillez. Sin reducirlas a entidades metafisicas Este va a sr un buen punto de partida para el interés orteguiano por la fenomenologia y el abandono de una estética ideologizante y normativa como la neokantiana, que olvida las simples cosas, y naturalmente el arte que hay en las simples cosas, estando por ello incapacitad para comprender el más genuino arte español.

\section{3.- Las vanguardias en España}

En junio de 1912 publica Ortega un articulo titulado "Del realismo en pintura" en el que trata con claridad el nuevo arte. Cita una exposición en la que participaban algunos pintores jóvenes ${ }^{12}$ de nuevas tendencias cuya pintura fue rechazada por la critica, acusada de idealismo y de no retomar la tradición realista española. Arremete contra los criticos, tratándoles de inquisidores reaccionarios, y atacando de paso la idea del realismo como propia de lo español en pintura. Ejemplifica la falta de realismo en Velázquez y Goya. Ortega no se compromete en exceso con los nuevos pintores a los que aconseja que corrijan ciertas puerilidades y arcaismos, pero les anima a seguir con su idea:

"Arte no es copia de las cosas, sino creación de ideas"13.

Además de mostrar su interés por las nuevas formas artisticas en oposición a la critica predominante, ofrece alguna de las claves de su interpretación desde la filosofia neokantiana, el concepto de creación va a ser pocos años más tarde el concepto clave de uno de

\footnotetext{
${ }^{12}$ Parece que se refiere Ortega a la Exposición Nacional de ese año. En ella, a pesar de algunos intentos de introducir elementos vanguardistas, triunfó la pintura tradicional. Véase BRIHUEGA. Jaime, Las vanguardias artísticas en España 1909-1936. Madrid 1981 p. 177. Más importante fue la exposición de ese mismo año de la sala Dalmau en Barcelona que tuvo una gran resonancia.
}

${ }^{13}$ O.C., I p. 568. 
los movimientos artisticos de vanguardia introducido en España por Vicente Huidobro ${ }^{14}$.

Pero el ambiente del arte de vanguardia en España distaba mucho de ser favorable y aceptado. Al propio Ortega le interesan más por estos años las obras de Zuloaga. o la literatura de Azorín. Baroja o Valle Inclán. Aunque no nos debe pasar desapercibido que nuestro autor prologa en 1914, el libro de poemas El pasajero de José Moreno Villa que es considerado un precedente de la literatura del 27. Por otra parte en pintura, como señala José Maria Valverde $^{15}$ las vanguardias no tendrán un peso específico muy grande en el ámbito español, puesto que la atención mayoritaria estará centrada en los pintores académicos y tradicionales. Por más que los grandes pinceles de la vanguardia hubieran surgido de la España de estos años, enseguida saldrian al exterior sobre todo a Paris, donde alcanzarian su madurez y su resonancia.

José Carlos Mainer ${ }^{16}$ habla de una actitud antirromántica y antidecimonónica que se daria en Europa y en España en estos años y de la que Ortega es partícipe principal. Esta actitud, cuyo indice más radical podria ser el manifiesto futurista de Marinetti, publicado en español por la revista Prometeo de Ramón Gómez de la Serna en 1909, será constante en las vanguardias hasta mediados los años treinta.

A pesar de todo podemos encontrar en estos años importantes hitos de la cultura de vanguardia en Espana. Las primeras creaciones de Picasso en Barcelona, las exposiciones de la galeria Dalmau, donde, como se ha dicho, hay una primera gran exposicion cubista en 1912 y expone en 1922 Francis Picabia. La propia edición de los primeros números de revistas como la dadaista 291 que se publica por primera vez en Barcelona en el año 1917 en la que colaboró activamente el propio Picabia o la creacionista

\footnotetext{
${ }^{14}$ Para una excelente biografia del poeta chileno véase la revista Poesía número extraordinario 30-31-32. Invierno 1988-89 editada en Madrid por el Ministerio de Cultura.

${ }^{15}$ VALVERDE J. M. "La cultura" en Historia de España, vol. 11, "Alfonso XIIl y la segunda república". ed Planeta. Madrid, 1991, p. 222.

${ }^{16}$ MAINER J. C. La edad de plata (1902-1939) Ensayo de interpretación de un proceso cultural, Ed. Cátedra, Madrid, 1981. p. 176.
} 
Creación de Vicente Huidobro que publica su primer número en Madrid en el mes de abril de 1921 . Ya en 1918 habia aparecido el "creacionismo" consiguiendo en España la anuencia de Juan Larrea y Gerardo Diego. Tambiên por esta fecha apareció el "ultraismo" entre cuyos promotores estuvieron Jorge luis Borges, Guillermo de la Torre y Rafael Casinos Aussens ${ }^{17}$. Todos ellos son autores y obras de la más radical vanguardia que pasaron poco menos que inadvertidos para la cultura oficial de la época, de la que enseguida entró a formar parte Ortega, pero que consiguieron establecer un inicio del posterior desarrollo.

Más importantes fueron algunas iniciativas culturales que, sin ser de vanguardia, posibilitarian después, por su talante liberal y aperturista. la recepción de las vanguardias en el ámbito español e incluso la creación de vanguardias desde la cultura española: Se pueden citar entre otras: La Junta de Ampliación de Estudios fundada en 1907 y que haría posible la relación con la cultura europea de significados intelectuales españoles, y la Residencia de Estudiantes fundada en 1910 por Antonio Giménez Fraud. En ambas dos instituciones participó muy activamente nuestro autor colocándose asi en los lugares estratégicos para ser árbitro , maestro y juez de la nueva cultura española. Ortega no va a ser nunca un autor de vanguardia. ni siquiera un incondicional defensor del arte de vanguardia, pero si va a posibilitar teórica y prácticamente la recepción y creación del arte vanguardista en España, por ser referencia inexcusable para los españoles que pretendieron entender el arte nuevo.

\section{4.- Arte y fenomenologia}

Con frecuencia se ha relacionado el arte de vanguardia con el movimiento fenomenológico, $y$ hay grandes interpretaciones

\footnotetext{
${ }^{17}$ Para todo ello véase BRIHUEGA. op. cit. y también Manifiestos, proclamas, panfletos y textos doctrinales. (Las vanguardias artísticas en España (1910-1931). Cátedra, Madrid, 1989.
} 
artísticas desde esta doctrina fllosófica ${ }^{18}$. Aqui pretendo mostrar como la fenomenologia se convierte en el elemento fundamental del análisis que Ortega hace del arte de vanguardia, que visto desde esta perspectiva aparece con la inteligibilidad que requiere un filósofo de los fenómenos que analiza.

En el año 1911, Ortega vuelve a Alemania, esta vez a Marburgo, y según nos dice el mismo autor toma contacto con la fenomenologia de Husserl a la que dedicara sus lecturas y estudios en los años siguientes ${ }^{19}$. En 1912 sólo pudo leer las Investigaciones Lógicas, puesto que las Ideas no se publicarán hasta 1913. A su regreso y ya en este último año publica una serie de artículos con el título "Sobre el concepto de Sensación", y una conferencia en la Asociación para el progreso de las ciencias titulada «Sensación. construcción, intuición*, que son las primeras presentaciones de la filosofia de Husserl en el ámbito español ${ }^{20}$. Al año siguiente escribirá las Meditaciones del Quijote ${ }^{21}$, cuya génesis fenomenológica ha sido estudiada por Philip W. Silver ${ }^{22}$ y el "Ensayo de estética a manera de prólogon ${ }^{23}$. Del primer libro sólo me cabe citar las frases del profesor Mainer que dice que es "un libro trascendental en la historia del pensamiento español ${ }^{24}$, el segundo artículo atañe

${ }^{18}$ El propto MAINER en la obra ya citada, se reflere a ello "IEn el arte de vanguardial junto a la ruptura con lo meramente representativo se dio una búsqueda de lo elemental. lo puro, del dato último que supone la médula de todo fenómeno (como si al arte hubiera llegado el análisis elementalizado que Husserl proponia en sus Investigaciones lógicas)", p. 181. Por otra parte cabe citar el clásico estudio de J. P. SARTRE, L'imaginaire. Psychologie phenomenologique de l'imagination librairle. Gallimard, París, 1940.

19 0.C. VIII. p. 47.

${ }^{20}$ En O.C.. I y XII respectivamente. Para un análisis pomnenorizado desde la fenomenologia de la serie de artículos véase J. SAN MARTIN. "El primer texto de fenomenologia en español". Comentario al texto "sobre el concepto de sensación de Ortega" Inédito.

${ }^{21}$ O.C., I.

22 SILVER P.. Fenomenologias y razón vital. Génesis de Meditaciones del Quijote de Ortega y Gasset. Alianza Universidad. Madrid, 1978.

${ }^{23}$ O.C.. Vl, p. 247.

${ }^{24}$ MAINER, op. cit., p. 142. 
directamente a nuestro tema y lo vamos a comentar mas extensamente.

Como ya he dicho es un prólogo al libro El pasajero de J. Moreno Villa, poeta que al decir de J. M. Valverde es un precursor de los de la generación del 27. En efecto Ortega señala en varias ocasiones que se trata de un nuevo estilo y una nueva musa, pero a decir verdad no hace grandes elogios del poeta ni de su estilo, simplemente intenta exponer un nuevo concepto de arte que va a ser un concepto fenomenológico de arte.

En el primer parágrafo, aparece uno de esos temas, que surgen a veces leyendo a Ortega, que, aun escritos en otro contexto, se muestran terriblemente actuales y premonitorios. El primer parágrafo está dedicado a criticar la trivialización del objeto artístico.

Citando a John Ruskin uno de los primeros sociólogos del arte y defensor en Inglaterra de Turner y de los prerrafaelistas, Ortega señala unos años antes de la Bauhaus, el peligro del gusto actual por el arte industrializado, y el diseño pretendidamente artístico de los objetos cotidianos. Sin embargo,según creo, Ortega piensa que precisamente el arte de vanguardia va a resistirse a la domesticación y a la manipulación pragmatista y confortable. La falta de adecuación del nuevo arte a las necesidades pragmáticas asi como al gusto común y su dificultad para ser entendido y manejado, le proporcionarán, según debia pensar nuestro autor su propia categoria de auténtico arte. En eso Ortega se mantiene en posiciones clásicas respecto al arte. El arte es siempre reflexión, consciencia. Para conseguir una auténtico goce estêtico no sirve la simple actitud natural, hace falta una cierta inhabitualidad, un cierto incomodo, una cierta reflexión para vislumbrar eso que llamamos la belleza.

"Y hay quien no ha sufrido nunca la experlencla esencial de la Belleza. sólo así se explica que pueda alguien beber en vasos bellos"25.

${ }^{25}$ O.C., VI, p. 250. 
Todo pensar es un pensar sobre, toda imagen es una imagen de, y por lo tanto conlleva una cierta inautenticidad, no se trata pues de pensar el arte ni de construirlo, no se trata como dice Ortega citando a Lipps de considerar la experiencia artistica como una proyección de cierta intimidad del yo en el objeto de arte.. Cada cosa tiene su autenticidad. su profundidad que le es propia (su propio yo ejecutivo, su propia intimidad), el lenguaje habitual sugiere, aproxima a esa intimidad, la obra de arte, la muestra. La experiencia artistica consiste en "ver siendo por dentro las cosas en el acto ejecutivo de su propia intimidad"26. La experiencia artística no es por tanto una visión cotidiana, natural y anodina. pero tampoco es una construcción subjetiva, fruto de la reflexión. Estamos en el campo de la intuición fenomenológica.

Pero la intuición artistica no es intuición de realidades, porque los objetos estéticos son irrealidades y

"El arte es esencialmente IRREALIZACION (...) La peculiar manera que en cada poeta hay de desreallzar las cosas es el estilo.(..) el estilo procede de la Individualidad del yo, pero se proyecta en las cosas"27 $^{\text {"27 }}$

Carlos Bousoño resume perfectamente en su obra El irracionalismo poético (el simbolo ${ }^{2 s}$ la posición de Ortega frente a la metáfora y al irrealismo estético. Y aunque sea para criticarlas establece interesantes paralelismos entre las teorias estéticas de Ortega y las de los teóricos del creacionismo (Huidobro) y del cubismo $^{29}$. Para Bousoño es evidente la relación del irrealismo estético de Ortega con las doctrinas esteticistas del siglo XIX, pero sobre todo con el origen del cubismo como primer movimiento pictórico que rompia definitivamente con la realidad. Permítaseme

${ }^{26}$ CEREZO P.. La voluntad de aventura. Aproximación crítica al pensamiento de Ortega y Gasset. Ariel, Barcelona. 1984, p. 410.

${ }^{27}$ o.C., VI. p. 262.

${ }^{28}$ BOUSOÑO, C. El irracionalismo poético. (El símbolo). Gredos. Madrid. 1981. capitulo XVII.

${ }^{29}$ Véase también el artículo de Ortega "El punto de vista en las artes. Cubismo". En Revista de Occidente. Madril. febrero de 1924. 
la larga cita :"...el irrealismo, como pensamiento doctrinal, no cobra vuelo y verdadera popularidad entre los criticos hasta que la pintura, especialmente con la llegada del cubismo, manifestó con evidencia la posibilidad efectiva de llevar a la práctica tal tendencia mimética..... Una vez que la pintura demostró que podian darse de hecho obras de arte independientes (en un cierto sentido) de la realidad (colores "gratuitos" del fauvismo, cubismo, primeros cuadros abstractos) se hacia posible concebir como esencia del arte, eso que ahora semejaba manifestarse de un modo palmario en la pintura" 30

Si la filiación estética del irrealismo orteguiano puede ser la que nos explica Bousoño, y que vincula a nuestro autor con la corrientes de la estética de vanguardia. la filiación fillosófica del irrealismo es fenomenológica. Nelson Orringer dedica un capítulo de su libro sobre Ortega ${ }^{31}$ al Ensayo de estética.... y lo relaciona con $\mathrm{M}$. Geiger y su obra Beiträge zur Phänomenologie der ästhetischen Genusses, publicada en Jahrbuch für Philosophie und phänomenologische Forschung. I 1913. Las tesis de Orringer que enfrenta las ideas estéticas de Geiger y Ortega a las del mismo Husserl, pueden ser más o menos discutidas, pero lo que es evidente que este estudio coloca a la obra de nuestro autor en la perspectiva fenomenológica. Refutando asi la opinión de Julián Marias que consideraria precisamente que es en este artículo donde Ortega refutaria la fenomenologia ${ }^{32}$.

La cuestión central del arte como irrealización no es muy atendida por Orringer, pero curiosamente es una de las conclusiones a las que llega en $1940 \mathrm{~J}$. Paul Sartre después de sus trabajos sobre La imaginación y Lo imaginario. Sartre que por estas fechas tiene un buen conocimiento de las tendencias del arte de

${ }^{30}$ BOUSOÑO. op. cit.. p. 324. El autor continúa haciendo unos paralelismos literales entre Ortega y Huidobro muy sugerentes. Ortega "la belleza comienza sólo en los confines del mundo real". Huidobro: "la verdad del arte empieza alli donde termina la vendad de la vida".

${ }^{31}$ ORRINGER Nelson R.. Ortega y sus fuentes germánicas. Gredos. Madrid. 1979. Pp. $169 \mathrm{ss}$.

${ }^{32}$ MARIAS, J., "La primera superación orteguiana de la fenomenologia", en La escuela de Madrid. pp. 257-264. 
vanguardia escribe una psicología fenomenológica de la imaginación y en ella concluye en su último capitulo:

"la obra de arte es un Irreal (...) en un cuadro el objeto estétıco es un irreal (...) Sencillamente lo que se manifiesta a través de él lde un cuadro completamente abstractol es un conjunto Irreal de cosas nuevas de objetos que no he visto nI veré nunca, pero que no por eso dejan de ser objetos Irreales, objetos que no exdsten en el cuadro ni en ninguna parte del mundo pero que se maniflestan a través de la tela y que se han apoderado de ella por una especie de posestón. Y es el conjunto de estos objetos ideales lo que callncaré de bello." ${ }^{.33}$

La posición de Sartre es clara y muy conocida. Menos estudiado está el origen de esa posición, que el mismo Sartre apunta en su libro sobre La imaginación $r^{34}$. En efecto alli cita a Husserl como el renovador de toda la teoría clásica sobre la imagen, cuya influencia ha sido fundamental para la filosofia y la psicologia contemporánea. Y cita un texto, que dice deberia permanecer como clásico y que muy bien pudo inspirar las ideas que sobre este asunto ha defendido Ortega en El Ensayo de Estética y posteriormente en toda su obra. El pasaje de Husserl pertenece a las Ideas y en él se hacen consideraciones sobre la modificación de neutralidad y la fantasia.. ${ }^{35}$ Como ejemplo se cita la obra de Durero : "El caballero, la muerte y el diablo". Y se distinguen varios niveles de aproximación: En primer lugar está la percepción puramente material a la hoja del papel o al grabado como tal. En esta aproximación no hay nada de artístico, por mucho que, como Sartre hará notar, pueda haber un cierto placer sensorial. En segundo lugar la conciencia perceptiva es capaz de organizar las lineas y manchas que aparecen y conformar intencionalmente a partir de esa materialidad unas figuras más o menos recognoscibles. Esas figuras en si mismas no son

33 SARTRE J. P., Lo imaginario. Psicologia fenomenológlca de la imaginación. Losada B.A.. 1976. pp. 278-281.

34 SARTRE J. P., La imaginación, Ed. Sudamericana, B.A., 1973, Cap. 4 Husserl.

35 HUSSERL. Edmund. Ideen zu einer reúnen Phanomenologie und phanomenologischen Philosophle. Husserliana, Band III, \$ 111. "Neutralitatsmodifikation und Phantasie" Traducción de José Gaos en Fondo Cultura Económica. México, 1949. 
tampoco el objeto estético, aunque sean su realización o su significante, de hecho remiten a una realidad más allá de sí mismas:

Diesen sind wir in der ästhetischen Betrachtung nicht als Objeten zugewendet: zugewendet sind wir den 'in Bllde' dargestellten, genauer, den "abgebılldeten" Realltăten..." ${ }^{36}$

Esas imágenes conformadoras (abbildende Bildobjekt), en cuanto conformadoras no están ante nosotros como realidades, ni como irrealidades, sino como "quasiexistentes" como dice Husserl en la modificación de neutralidad del ser, es decir sin importarnos para nada su ser real efectivo, es decir, su materialidad como colores tintas e incluso formas.Lo importante de ellas es que conforman algo a lo que remiten. Pero la misma circunstancia se da para las realidades conformadas (Abgebildete) que desde un punto de vista puramente estético son importantes como mera conformación, pero no su efectiva existencia o inexistencia. ${ }^{37}$

Probablemente sea éste el origen filosófico de la teoria del arte como irrealidad que Ortega expone y mantiene a lo largo de su obra.

Naturalmente esta especificidad del objeto artístico que rechaza ser reducido a cualquier otro, y esta irrealidad en el arte que por una parte no tiene porque copiar nada existente-natural, y por otra parte rechaza ser interpretado como proyección de elementos de la subjetividad humana, conforma un arte que Ortega creia puro, indomesticable, pero dificil de entender y asumir por las personas, aún cultas, de su tiempo.

Por ello en un ensayo de $1921^{38}$. Ortega constata que últimamente se encuentra una cierta incapacidad para el goce artístico entre las personas cultas de Europa.

El cambio se ha dado también en nuestra actitud hacia el arte, antes proyectábamos en él nuestros sentimientos y emociones y buscábamos ocultas grandezas prometidas, que como obra artística

\footnotetext{
${ }^{36}$ HUSSERL. Op. cit.. 269 (tr. 262).

37 HUSSERL. op. cit.. p. 269-270 (tr. 263).

38 "Apatia artística", O.C., II.
} 
debia poseer. Antes juzgábamos la obra de arte respecto a ideas preconcebidas. Ahora

"En vez de proyectar trabajosamente sobre ellas lo que no poseian, esperamos con pasivo temperamento a que ellos (los objetos artisticos) nos conquisten, si son capaces ${ }^{139}$

$\mathrm{El}$ goce que produce el arte nuevo es distinto al producido por el arte romántico. De nuevo opone Wagner a Strawinsky. Con el primero
"sentiamos un patetismo universal: nuestro organismo creía tomar contacto con las venas secretas del mundo y sumirse en el aliento cósmico(...) Por el contrario la música de Strawinsky, reduclendo sus aspiraciones, logra proveernos de goces más auténtıcos. ${ }^{.40}$

Parece que aqui Ortega, haciendo un análisis, no de las obras, sino de la actitud del que las escucha, refiere la primera a un tipo de estética hegeliana que se plantea la universalidad del hecho artístico, mientras que la segunda no la asocia con nada ( y seria interesante asociarla con la visión fenomenológica del arte). La universalización de la obra artística fue un resultado de la llustración (cita a Goethe y Diderot) y se realiza con toda su fuerza en el romanticismo (cita a Wagner proponiendo su arte como sustituto de la religión). Antes el arte tenia su lugar secundario entre las actividades humanas.

En esta actitud romántica hay un error de perspectiva vital. Un error que Ortega analizará de un modo tipicamente fenomenológico, y que desde este análisis se puede entender toda la critica posterior de la "Deshumanización del arte"

La perspectiva es un modo de acceder a las cosas, pero cada cosa tiene su gradación y su perspectiva correcta. Cada cosa se nos da en su autenticidad desde una perspectiva

${ }^{39}$ O.C.. II. p. 336.
${ }^{40}$ o.C.. II. p. 336. 
"El error está en suponer que puede nuestro albedrio decidir cuales cosas han de ocupar el primer plano, cuales el segundo y así sucesivamente" ${ }^{\text {"41 }}$.

por ejemplo pensar que el arte es una buena perspectiva para conocer la realidad de las cosas en su esencia parece un despropósito.

Cualquier forma de atención requiere una gradación en la atención . primamos unos objetos o temas y descuidamos más otros. $\mathrm{Y}$ es fundamental acertar en esa gradación de nuestros intereses. Las cosas tienen su peculiar grandeza cada una en si misma. Pero se resisten a ser todas de grandeza absoluta. El saber mirar una cosa es precisamente saber concederle la importancia que ella misma tiene, y hacerla brillar en toda la intensidad de luz que le es propia, colocarla en un alto valor. o en un valor absoluto o concederle una gran dignidad que ella no tiene y que en su ser le es ajena, es hacerla miserable y desfavorecida. Todo esto tiene mucho que ver con lo que se ha dicho en Las Meditaciones del Quijote y es estricta fenomenologia.

En el arte romántico en general hay una excesiva ambición expresiva. Los valores estéticos son tan excesivos que requieren una abstracción de nuestra propia situación personal. no otra cosa es la situación que debe adoptar el espectador de arte en nuestro mundo. Una sala insonora, silencio. asistencia especifica para oir., etc.. la realidad artística y estética puede sin embargo hacerse presente en cualquier lugar, inesperadamente, sin buscar situaciones puras ni especiales. Cortázar escucha apasionadamente jazz en un giradiscos viejo con ruido de fondo, y Ortega nos narra como un violin de un ciego puede punzarnos el corazón.

Según parece y coherentemente con lo dicho en anteriores ensayos Ortega no renunciaria aqui al valor estético que se da en el nuevo arte, sino que lo adecuaria a su auténtico valor en cada una de sus expresiones. Las artes deben encontrar de nuevo su lugar

${ }^{41}$ O.C.. II, p. 337. 
"los siglos prudentes situaron la música al fondo de un banquete, en el rincón del sarao o tras las ramas de un jardin"42.

En el mismo año 1921 aparece el artículo "Musicalia". Ortega comienza constatando que el público continua aplaudiendo a Mendelsohn y siseando a Debussy. La nueva música no es popular. La música de Wagner fue impopular y ahora se ha hecho popular, la música de Debussy, será según cree Ortega siempre impopular. Ortega vuelve a equivocarse sobre las imposibilidad de trivializar el arte contemporáneo. (Véase si no las copias que se han hecho de las más famosas obras del músico).

Se lanza a consideraciones sobre la aristocracia del gusto y el sinsentido de la igualación en derechos de todos los hombres. Hace interesantes comparaciones entre la "VI sinfonia" de Beethoven y el "Preludio a la siesta de un Fauno" de Debussy, adjudicando al primero el gusto burgués y al segundo el cambio de lenguaje artístico.

"El arte evoluclona Inexorablemente en el sentido de una progresiva purfflcación; esto es se va ellminando de su Interior lo que no es puramente estético"43.

De nuevo comparando la música de Mendelsohn y la de Debussy trae a colación como el romanticismo adoba artísticamente los sentimientos vulgares, y la nueva música y el nuevo arte exalta lo puramente artístico.

"Se trata de dos estilos que expresan estratos de sentimientos muy distantes entre sí. Para el uno, es arte la bella envoltura que se adosa a lo vulgar. Para el otro es arte un arisco imperattvo de belleza integral. (...) el honrado público que aplaude la marcha nupcial y silva la Iberia del egregio moderno ejerce un terrorismo artístico"44.

\footnotetext{
42 0.C.. II. p. 339. Publicado en El espectador III, 1921.

${ }^{43}$ O.C., II. p. 242.

${ }^{44}$ o.C. . II. p. 242.
} 
Ortega erigido en árbitro del nuevo gusto, retoma sus antiguos argumentos en contra del romanticismo y de su proyección de emociones y sentimientos en la obra de arte. La música romántica nos interesa por las emociones y repercusiones que en nosotros provoca, no nos interesa por la música misma

"En clerto modo gozamos pues no de la música, sino de nosotros mismos"45.

La música de Debussy como la de Strawinsky nos invita a poner el oído en los sonidos mismos y a desprendernos de nuestros particulares sentimientos.

"Gozamos la nueva música en concentración hacia afuera. Es ella lo que nos interesa, no su repercuslón en nosotros"46.

Y concluye Ortéga colocando en un nivel secundario aquel arte cuyo objeto es inducir en el espectador determinados sentimientos o emociones, ese arte es secundario, repercutido.

" todo placer originado en una sugestión mecánica, en un contagio, es infimo porque es inconsciente. No se goza en él de la obra que lo produce, sino de su efecto clego. (...) Arte es contemplaclón, no empujón"47.

Esta idea del arte como contemplación enlaza precisamente con la verdad como desvelamiento de las Meditaciones y con la intuición originaria fenomenológica.

\section{5.- La deshumanización del arte}

Ortega escribe este libro con una voluntad confesada de comprensión-explicación de las artes de vanguardia. y lo hace en una fecha en la que ya hay una perspectiva suficiente, incluso en

\footnotetext{
${ }^{45}$ o.C.. II. p. 243.

${ }^{46}$ o.C. p. 243.

47 O.C., p. 244.
} 
España, para conocer los movimientos esenciales de las nuevas tendencias artísticas. Es tambiên evidente que a estas alturas Ortega ya ha elaborado una parte sustancial de su sistema, y como él mismo se encargará de decir, este libro no puede interpretarse más que como un parte de su racio-vitalismo y perspectivismo ${ }^{48}$, ahora aplicado a uno de los fenómenos de nuestro tiempo.

En general el libro no es una confesión de entusiasmo por las vanguardias artisticas. Ortega no se coloca nunca en situación entusiástica respecto a ellas, más bien, parece la obra del crítico cultural desinteresado emocionalmente, pero con clara voluntad de comprender y asumir un fenómeno que a esas alturas ya es de gran resonancia. Tampoco creo que sea completamente cierto. como dice el profesor Mainer, que Ortega se mantuviera a estas alturas "fiel a ese realismo critico, intelectual y nacionalista que se habia identificado con la revista España"49.

Lo que si es evidente que el libro tuvo una gran influencia sobre la intelectualidad española, siendo la inspiración de la mayor parte de los tratados que se escribieron sobre las vanguardias artisticas, así como impactó de forma notable a los propios artistas de vanguardia españoles ${ }^{50}$

El año 1925, como dice Francisco Calvo Serraller ${ }^{51}$, es decisivo en la historia del arte de vanguardia español y en especial del surrealismo. Además de la publicación del libro de Ortega se publica ese año el de Guillermo de la Torre: Literaturas europeas de vanguardia y aparece el primer número de la revista Plural.

También se produjo ese año la Exposición de la Sociedad de Artístas Ibéricos que se inauguró el 28 de mayo en el Retiro madrileño. Para esta exposición se redactó un manifiesto firmado por los artistas mas modernos del tiempo que a decir de JC. Mainer

\footnotetext{
${ }^{48}$ O.C., IV. p. 390.

49 MAINER, Op. cit., p. 187.

${ }^{50}$ Véase MAINER op. cit.. p. 187 ss. El mismo Luis BUÑUEL pide desde París el libro en carta de 10-2-1926 a la libreria de León Sánchez Cuesta.

51 CALVO SERRALLER. Francisco. "Salvador Dali y la vanguardia artistica española de los años veinte". En Dalh, Museo Español de Arte contemporáneo. Palau relal de Pedralbes. Barcelona, 1983.
} 
eran mas vanguardistas los literatos que los propios pintores ${ }^{52}$. También de esta exposición Hizo un comentario Ortega en el periödico "El Sol" titulado "El arte en presente y en pretérito" que tuvo gran resonancia. Todo lo cual significó para el arte de vanguardia , su reconocimiento y consolidación, consiguiendo una cierta institucionalización del nuevo arte. Consolidación que no siempre es bien vista por los propios vanguardistas españoles, que al igual que André Bretón por esas fechas denunciaban o mejor satirizaban del oficialismo artístico.

Ortega retoma de nuevo el tema de que el nuevo arte es impopular y asocia a las nuevas tendencias artistica europeas bajo el "mismo impulso biológico". Y, confesadamente, desde una perspectiva de sociologia del arte, se plantea que una de las caracteristicas que las une es su impopularidad. La cuestión no es de gustos, sino de entendimiento. La mayoria de las gentes no entienden el arte nuevo, y para Ortega esa es una de sus principales caracteristicas. Parece que Ortega cuando se refiere a la popularidad del arte en realidad está pensando en que no gusta al hombre burgués medio, a lo que después va a llamar las masas

"El arte joven, con sólo presentarse, obliga al buen burgués a sentirse tal y como es: buen burgués, ente incapaz de sacramentos artísticos, clego y sordo a toda belleza pura"53

Pone los ejemplos de STRAWINSKY o PIRANDELLO y enuncia la teoria de las minorias selectas que deben dirigir a las masas burguesas. Naturalmente Ortega generaliza estos principios y los amplia desde el arte al conjunto de la politica y la sociedad.

Analiza Ortega la forma de goce artístico del común de los mortales y concluye que para ellos el goce artistico se encuentra en la identificación o desidentificación de lo representado con lo real. Lo representado artisticamente dice algo a la gente sobre su realidad sobre sus sentimientos o sobre su medio, eso le hace

\footnotetext{
52 Véase BRIHUEGA, Las vanguardias, p. 256 ss. y en Maniflestos.... "Salón de Artistas ibéricos. Maniflesto" p. 114 ss.

53 o.C.. III. p. 355.
} 
identificarse o desidentificarse con ello. Pero eso es ajeno a lo puramente artistico

"Alegrarse o sufrir con los destinos humanos que, tal vez, la obra de arte nos reflere o presenta, es cosa muy diferente del verdadero goce artístico.Mas aún: esa ocupación con lo humano de la obra es, en principlo, incompatible con la estricta fruición artística" ${ }^{45}$.

Aqui Ortega introduce una reflexión puramente fenomenológica en cuanto dice que el arte requiere una mirada propia. Lo artistico requeriria una mirada especial y activa para ser visto. Se da de un modo propio, distinto al modo emocional o sentimental, y desde luego distinto al realista. Retoma al propio tiempo su tema del arte propiamente artístico, y la irreductibilidad del arte y su irrealidad:

"Pero es el caso que el objeto artistico sólo es artístico en la medida en que no es real"s5.

El arte puro es pura virtualidad, y tiene una entidad por si mismo independiente de toda concreción vital humana. Ortega duda que exista un arte puro. Pero piensa que las modernas tendencias artísticas han tendido a depurar el arte antiguo liberándolo de antiguas servidumbres e impurezas. Cree el autor que estas nuevas tendencias artísticas son la representación de las nuevas épocas históricas y son coherentes con ellas mismas. A continuación da las famosas siete tendencias del nuevo arte:

"Si se analiza el nuevo estilo, se hallan en él ciertas tendencias sumamente conexas entre si. Tienden: $1^{2}$, a la deshumanización del arte; $2^{\mathbf{2}}$, a evitar las formas vivas; $3^{\mathbf{2}}$, a hacer que la obra de arte no sea sino obra de arte: $4^{\circ}$, a considerar el arte como juego, y nada más; $5^{2}$, a una esenclal Ironia; $6^{2}$, a eludir toda falsedad, $y$, por tanto a una escrupulosa realización. En fin $7^{\circ}$, el arte, según los artistas jóvenes, es una cosa sin transcendencla alguna" ${ }^{\prime 56}$.

\footnotetext{
54 O.C., III, p. 357.

${ }^{55}$ o.c., IIl, p. 358.

${ }^{56}$ 0.C., III, p. 360.
} 


\section{6.- La fenomenologa en gotas}

Ortega vincula explícitamente su ejemplo de perspectivismo con el método fenomenológico y lo aplica para concluir lo siguiente:

1 Hay una perspectiva fundamental y fundante de las otras, es la perspectiva de la vivencia del hecho. Es la vivencia originaria (Ortega dirá vivida) y es la que fundamenta a las demás. Hay una forma primigenia (Por ejemplo la forma primigenia de la manzana es la que tiene cuando nos disponemos a comerla) todas las demás son secundarias y derivadas.

$2^{\circ} \mathrm{El}$ arte nuevo tiende a desasirse de las vivencias humanas. y su actitud seria la paralela a la del científico que contemple cualquier realidad sólo desde los esquemas de su propia ciencia. También esto nos parece inhumano. Toda realidad tiene en sí misma un valor artístico independientemente de su valor humano. sin embargo el valor artístico de las cosas se da en la realidad como secundario al valor humano.

Existe pues una nueva sensibilidad estética. Esto es lo que interesa a Ortega que sólo tiene una mediana opinión de cada una de esas nuevas tendencias y que se desinteresa por las obras particulares. Le interesa más la nueva estética como elemento genérico, y encuentra que es caracteristica de esta nueva estética. la deshumanización del arte. (natural = humano)

Ortega parece describir que el método del nuevo arte es una especie de epojé fenomenológica en la que progresivamente se van perdiendo los caracteres de realidad fáctica y lo que se expresa es una cierta forma de idealidad y de pureza que expresando una realidad lo hace prescindiendo de sus caracteres más naturalistas y obvios

.....lograr construir algo que no sea copla del "natural" y que, sin embargo, posea alguna sustantividad, Implica el don más sublime" ${ }^{15}$.

57 o.C., III, p. 366. 
Ortega cita, sin embargo, como fracasos los intentos de Picasso de construir un arte completamente abstracto, asi como la "broma'dadaista". Lo que nos permite ver que aunque la dirección de la critica artistica de vanguardia podia ser la correcta quizás no fue apurada hasta el final. Es necesaria, sin embargo, una invitación a comprender.

Ortega se confiesa innovador y hace criticas genéricas a la antigua sensibilidad artistica frente a las nuevas formas. Dice que no hay que anquilosarse y, como apuntaba el profesor Mainer. muestra un compromiso más histórico que entusiasta. Se trataria para él de estar, también en arte a la altura del siglo. Por otra parte insiste en su concepción básica de la irrealidad del arte

. "Todas las grandes épocas del arte han evitado que la obra tenga en lo humano su centro de gravedad. Y ese imperativo de exclusivo realismo que ha gobernado la sensibllidad de la pasada centurla significa precisamente una monstruosidad sin ejemplo en la evolución estêtıca"58

Por lo tanto la actual evolución artística enlaza con las grandes épocas del arte en lo que se llama "voluntad de estilo" Pero estilizar significa desrealizar y la estilización es una forma de desrealización, y a esto es a lo que Ortega llama deshumanización.

Más adelante dice que lo humano es "el repertorio de elementos que integran nuestro mundo habitual". Uno de los elemento básicos de lo humano es el sentimiento. Todas las cosas están llenas de sentimientos y el arte actual se propone liberarnos del sentimiento de las cosas. Especialmente la música antigua es la música del sentimiento, es la música-biografia, el melodrama. Y Ortega critica la música romántica como música con trampa, en cuanto atañe a algo sentimental y por lo tanto no artistico

"el llanto y la risa son estéticamente fraudes"59

\footnotetext{
${ }^{58}$ O.C., III. p. 367-68.

${ }^{59}$ o.C.. III, p. 369.
} 
Ortega compara la alegria del borracho y la del premiado en la loteria. El borracho no tiene un motivo particular de su alegria. la siente en sí mismo. El premiado se alegra "de". Es decir la alegria del premiado es una alegria intencional que precisa una contenido real objetivo y exterior. La estética romántica premia la borrachera de la alegria en cuanto yo la siento interiormente.

"En vez de gozar del objeto artístico, el sujeto goza de sí mismo; la obra ha sido sólo la causa y el alcohol de su placer. Y esto acontecerá slempre que se haga consistir radicalmente el arte en una exposlción de realidades vividas. Estas sin remedio, nos sobrecogen, suscitan en nosotros una particlpaclón sentimental que impide contemplarlas en su pureza objetiva"60

Cada arte realiza las cosas de las que trata de una forma peculiar. Las figuras extremadamente realistas, como son las figuras de cera no nos producen la sensación de realidad, pero se parecen tanto a la realidad!, son las preferidas de la gente. El nuevo arte prescinde de esos aspectos tan concretos de la vida '(humanos!). Tiene asco de lo concreto humano, se va a construir lo estilizado, lo formal lo puramente expresivo sin ninguna connotación y por tanto sin ninguna contaminación. Pone como ejemplo e iniciación la música de Debussy. frente a la de Wagner y la poesia de Mallarmé frente a la poesia romántica. En realidad es el arte puro lo que se preconiza. Ortega entra en una polémica que interrumpe: $¿$ Para el arte nuevo la vida es desdeñable y por eso se prescinde de ella? o más bien la vida es tan importante que el arte como producto subalterno sólo puede dejarla a un lado. Aunque no lo diga parece que Ortega admite que en efecto el arte actual busca su autenticidad en lo puramente artístico y por lo tanto se ha convertido en una arte formal, que intenta expresar la belleza por si misma sin más implicaciones de cosas o sentimiento y emociones concretos, eso no quiere negar que la vida sea en efecto más importante y más expresiva que el propio arte que no seria más que una abstracción parcial, un elemento secundario de la vida.

${ }^{60}$ o.C., III, p. 369. 
Ortega prosigue sus indagaciones sobre la metáfora colocándola en el centro del nuevo arte. La hace coherente con su teoria general del arte como irrealidad. (José Maria Valverde corrige a Ortega precisando que éste se equivoca al considerar que la clave de las vanguardias es la metáfora, él propone a la imagen). ${ }^{61}$

"La metáfora escamotea un objeto enmascarándolo con otro, y no tendria sentido, si no viéramos bajo ella un Instinto que induce al hombre a evitar realldades"62

desde el interés orteguiano de presentar al arte y más al arte nuevo como desrealización, la acepción de la metáfora incide sobre todo en lo que tiene de "privación de una realidad". Véase la doctrina sobre la metáfora de Ortega en Marias y Bousoño.

En la nueva concepción poética la metáfora es sustancia y no ornamento, pasa de ser un instrumento poético para expresar algo a ser objeto propio del arte poético. La metáfora es el instrumento más radical de deshumanización. Otro es el simple cambio de perspectiva habitual. Humanizar desde luego aqui no tiene ningún tipo de connotación genérica o abstracta. Mas bien lo contrario. Humanizar significa el punto de vista corriente, dominante, general, e incluso vulgar. Cambiar la perspectiva habitual no es renunciar a la realidad, sino presentar otro plano de lo real. El extremar el realismo significa superarlo. ese es el papel de la fenomenología. La realidad habitual no es más que la posición de un mundo desde la actitud natural. El artista evidentemente prescinde de la actitud natural y por eso estiliza, pero no necesariamente idealiza, ni siquiera, desrealiza, simplemente presenta una nueva visión de la realidad que es pregnante y artisticamente valiosa.

"a la ascensión poética puede sustituirse una inmersión bajo el nivel de la perspectiva natural. Los mejores ejemplos de cómo por extremar el realismo se le supera-no más que con atender lupa en

\footnotetext{
${ }^{61}$ VALVERDE, op cit.. p. 196.

62 o.C., III, p. 373.
} 
mano a lo microscópico de la vida- son Proust, Ramón Gómez de la Serna, Joyce ${ }^{163}$

La metáfora se ha convertido en la res poética. Lo que antes era procedimiento artístico se revela ahora como el propio objeto del arte. Referencia filosófica interesante de las ideas a la realidad.

"Con las Ideas, pues, vemos las cosas, y en la actitud natural de la mente, no nos damos cuenta de aquéllas, lo mismo que el ojo al mirar no se ve a sí mismo. Dicho de otro modo, pensar es el afán de captar mediante ideas la realidad; el movimiento espontáneo de la mente va de los conceptos al mundo.

Pero es el caso que entre la ldea y la cosa hay slempre una absoluta distancla. Lo real rebosa slempre del concepto que intenta contenerlo. El objeto es slempre más y de otra manera que lo pensado en su idea. Queda esta slempre en un misero esquema, como un andamiaje con que intentamos llegar a la realidad. Sin embargo la tendencla natural nos lleva a creer que la realidad es lo que pensamos de ella, por lo tanto, a confundirla con la idea, tomando ésta de buena fe por la cosa misma. En suma, nuestro prurito vital de realismo nos hace caer en una Ingenua realización de lo real. Esta es la propensión nativa, "humana"64.

Aqui Ortega parece reducir su concepto de "humano" a lo que en fenomenologia se llama la "actitud natural" que consiste en atribuir sin más realidad objetiva a lo que pensamos de las cosas, en definitiva de presuponer directamente una identidad entre pensamiento y realidad. esta actitud natural no acepta ningún planteamiento formalista, lo mismo que no acepta un planteamiento cientifista. Y propone que en Arte contemporáneo lo que se hace es dar la vuelta a esa actitud natural,: expresando lo que son meros esquemas ideales, como realizaciones artisticas. Con ello se desrealiza la realidad, pero también se desnaturaliza la idea que sirve para ser idea y no para ser concretamente objetivada "es realizar lo irreal en cuanto irreal" (p. 367).

\footnotetext{
${ }^{63}$ O.C.. III. p. 374.

64 O. C.. III, p. 375-376.
} 
Cita al cubismo, al expresionismo. A Pirandello (Seis personajes en busca de un autor) lo coloca como el paradigmático "drama de ideas" en lugar de drama de personajes. en realidad en esta obra es la idea del teatro la protagonista y no las pseudopersonas que antes simbolizaba ideas

En el nuevo arte hay una oposición a las tradiciones artisticas del pasado una agresividad hacia ellas. Hay de nuevo una reivindicación de lo ingenuo de lo primitivo y de lo que no tiene tradición. En esta reivindicación de lo salvaje Ortega entreve un cierto anticulturalismo o lo que después se llamará un contracultura. Un odio no a un estilo u otro de arte, sino al arte mismo y a la cultura misma.

Ortega compara sus dos grandes conclusiones sobre el nuevo arte. Por una parte el nuevo arte quiere prescindir de todo lo que es accesorio y circunstancial para retener la expresión artistica pura libre de connotaciones ajenas a la propia idea de arte. Por otro lado Ortega descubre un cierto primitivismo y salvajismo y ruptura explicitamente buscada con toda la tradición artistica e incluso con la propia idea de arte. esto es lo que supone un destino irónico del nuevo arte. Se asume consciente y consecuentemente la idea del arte como irrealidad como "farsa", el arte se revuelve contra si mismo y al considerarse como farsa ataca su propia realidad y se vuelve autocrítico de la propia idea de arte. Pero;

"Nunca demuestra el arte mejor su mágico don como en esta burla de sí mismo. Porque al hacer ademán de aniquilarse a sí propio sigue siendo arte, y por una maravillosa dialéctica, su negación es su conservaclón y trlunfo"65.

El arte actual rompe con la idea hegeliana de que en el arte se expresa lo universal. El arte actual pierde su empaque y su grandilocuencia. No se plantea conscientemente problemas universales, sino que recupera el sentido lúdico e informal, creativo y alegre de lo primitivo y lo infantil. La flauta de pan es el simbolo del arte nuevo. y los juegos y los deportes las realidades sociales mas significativas con las que se puede parangonar.

${ }^{65}$ O.C., IIl, p. 382. 
El culto a la juventud, y al cuerpo ágil y bello, serian caracteristicas del arte nuevo. "..El cinematografo es por excelencia, arte corporal"

\section{A modo de conclusión}

En este trabajo he intentado mostrar las aportaciones que Ortega hizo al arte de vanguardia español, y sus posiciones respecto a este movimiento hasta la publicación de la Deshumanizacion del arte, obra que fijaria sus opiniones al respecto.

La aportación teónica de Ortega fue decisiva e influyó poderosamente en el ámbito hispano en la forma de comprender y de aceptar el nuevo arte. Pretendo mostrar que esa comprensión teórica está orientada desde un punto de vista fenomenológico, y aún supone una aportación importante y temprana a la estética producida desde la fenomenologia, que otros autores posteriormente seguirian y completarian.

También es necesario decir con claridad que no se puede considerar a Ortega como un militante ni un entusiasta del arte de vanguardia, como no fue ni hombre de partido ni hombre ejemplar en ningún tipo de movimiento. Ortega observa el nuevo arte e intenta explicarlo y comprenderlo como un fenómeno a la altura del tiempo, pero siempre con la suficiente distancia para mantener una frialdad que posibilitara una serena critica, así como con la madurez y el prestigio intelectuales como para erigirse en muchos momentos en árbitro sobre su calidad o conveniencia. Por su actitud y su edad, Ortega se convertirá para los vanguardistas españoles en un maestro orientador y respetado, pero un tanto ajeno a su propia peripecia intelectual mucho más vehemente, comprometida y radical. Con las evidentes ventajas y riesgos que ello supone.

La critica orteguiana del arte ha quedado un tanto desdibujada por êl mismo por dos puntos fundamentales: En primer lugar

${ }^{66}$ 0.C. . III. p. 384. Pocos años después en el año 1927, organizaba la Residencia de estudiantes una conferencia de Luis Buñuel (que habia llegado de Paris) con posterior proyección de peliculas de la vanguardia parisina. Ortega asistió a la conferencia y a la proyección. llamando posteriormente al cineasta aragonés y mostrándole su interés y su aprobación por lo que alli se habia visto y escuchado. 
porque en su conceptualización del arte como irrealización es a veces un tanto dubitativo e, influido por Husserl, mantiene siempre un resto de realidad en la expresión artistica y por eso considera que la metáfora es elemento fundamental del arte de vanguardia. Sartre siguiendo muchos años después los mismo pasos hará una conceptualización más radical y clara, que sólo consistirá en el desarrollo de lo que aquí estaba ya planteado, pero no se llevó a termino de forma decidida. En segundo lugar el mezclar el aspecto fundamental de irrealidad con el más anecdótico de incomprensión por unos o por otros o incluso con el completamente erróneo de la imposibilidad de trivialización ha hecho que la estética orteguiana haya sido mal vista por muchos autores del pasado y del presente. En este trabajo pretendo ofrecer la gradación adecuada, para que el trabajo de crítica estética de Ortega se contemple en su verdadera importancia como un intento de la estética fenomenológica de penetrar critica y racionalmente en un terreno tan dificil como el arte de vanguardia. 